\title{
Instructional Support for Enhancing Students' Information Problem Solving Ability
}

Citation for published version (APA):

Brand-Gruwel, S., \& Gerjets, P. (2008). Instructional Support for Enhancing Students' Information Problem Solving Ability. Computers in Human Behavior, 24(3), 615-622. https://doi.org/10.1016/j.chb.2007.01.020

DOI:

10.1016/j.chb.2007.01.020

Document status and date:

Published: 01/05/2008

Document Version:

Peer reviewed version

Please check the document version of this publication:

- A submitted manuscript is the version of the article upon submission and before peer-review. There can be important differences between the submitted version and the official published version of record. People interested in the research are advised to contact the author for the final version of the publication, or visit the DOI to the publisher's website.

- The final author version and the galley proof are versions of the publication after peer review.

- The final published version features the final layout of the paper including the volume, issue and page numbers.

Link to publication

\section{General rights}

Copyright and moral rights for the publications made accessible in the public portal are retained by the authors and/or other copyright owners and it is a condition of accessing publications that users recognise and abide by the legal requirements associated with these rights.

- Users may download and print one copy of any publication from the public portal for the purpose of private study or research.

- You may not further distribute the material or use it for any profit-making activity or commercial gain

- You may freely distribute the URL identifying the publication in the public portal.

If the publication is distributed under the terms of Article 25fa of the Dutch Copyright Act, indicated by the "Taverne" license above, please follow below link for the End User Agreement:

https://www.ou.nl/taverne-agreement

Take down policy

If you believe that this document breaches copyright please contact us at:

pure-support@ou.nl

providing details and we will investigate your claim.

Downloaded from https://research.ou.nl/ on date: 26 Apr. 2023 
Running head: INFORMATION PROBLEM SOLVING

This article was published as:

Brand-Gruwel, S., \& Gerjets, P. (Eds.). (2008). Instructional Support for Enhancing Students' Information Problem Solving Ability [Special issue]. Computers in Human Behavior, 24(3).

Copyright Elsevier, available online at

http://www.elsevier.com/wps/find/journaldescription.cws_home/759/description\#description

Instructional Support for Enhancing Students' Information Problem Solving Ability

Saskia Brand-Gruwel

Open University of the Netherlands

Peter Gerjets

Knowledge Media Research Center, Tuebingen, Germany

Correspondence concerning this article should be addressed to Saskia Brand-Gruwel, Open University of the Netherlands, Educational Technology Expertise Center, PO Box 2960, 6401 DL Heerlen, The Netherlands. E-mail: saskia.brand-gruwel@,ou.nl 


\begin{abstract}
This special issue discusses European research on instructional support to foster students' ability to solve information-based problems. In this introduction, the concept of information problem solving (IPS) and research in this field of interest will be placed in the broader perspective, which is called information behavior. The focus of this special issue is an educational one and the papers all go into a specific kind of instructional support. The main research questions, findings and conclusions of the six contributions will be outlined. It is concluded that the most important directions for future research deal with how instructional support for different aspect of the process, like for instance how to regulated the process, best can be designed in order to make the instruction adaptive and fit to the learners needs.
\end{abstract}


Introduction

The European Association for Research on Learning and Instruction (EARLI) organizes a bi-annual conference to provide a platform for the presentation of educational research - with a strong focus on research conducted in Europe. During the conference held in 2005 on Cyprus (Greece) we organized a symposium concerning instructional support to foster students' ability to solve information-based problems. Solving information-based problems require from students to identify information needs, locate information sources, extract and organize information from each source, and synthesize information from a variety of sources. This set of activities is frequently defined as Information problem solving (IPS) (Eisenberg \& Berkowitz, 1990; BrandGruwel, Wopereis \& Vermetten, 2005; Moore, 1995; Wolf, Brush \& Saye, 2003) but also as information literacy (Bawden, 2001; Marchionini, 1999; Shapiro \& Hughes, 1996; Spitzer, 2000).

Research in this field of interest primarily focused on how students search for information using different kind of databases and sources, and a lot of research in this field is conducted from a Library and Information Science perspective (LIS). More recently research focus on the whole process of information seeking or information problem solving, not only the search of information but also the judging, processing, organizing and presenting information is object of study (Brand-Gruwel et al., 205; Kuhltau, 2004). In the last decennia research emerge from an educational point of view focus on how students can be fostered and stimulated to become more able in solving information-based problems (Eisenberg \& Berkowitz, 1990, 1992, 2000; Eisenberg \& Johnson, 2002). Different instructional design principles are used to design programs for solving information problems for all kinds of students (primary, secondary, tertiary). The papers presented during the conference give an excellent impression of the kind of 
research on instructional support fostering students' information problem solving ability that is currently conducted in Europe. Accordingly, we considered to make this overview available for a broader public, and intended to publish the set of papers as a Special Issue. We are grateful that Computers in Human Behavior was willing to consider this set of papers for publication.

This Introduction to the Special Issue will first discuss the concept of information problem solving. The research concerning IPS and designing programs for fostering this skill will be placed in a broader perspective. Second, the contributions to this Special Issue will be put in context within the European educational field. The main research questions, findings, and conclusions of each contribution are briefly outlined. Third, some general conclusions and directions for future research are formulated.

\section{Information problem solving}

In the last decades the process of solving information problems has been extensively studied. Wilson (1999) describes a series of three "nested" research fields, which makes it possible to place the research on information problem solving in a broader perspective. Research on information problem solving is best placed within the research field of 'information-seeking behavior'. Research in this area is aimed at unraveling human behavior while searching, acquiring, processing, organizing and presenting information (Kuhltau, 1993). A sub set of 'information-seeking behavior' is 'information-searching behavior'. Research within this field is focused on clarifying the process of searching and locating information (Hill, 1999; Hölscher \& Strube, 2000; Lazonder, 2000, 2003; Marchionini, 1995; Sutcliffe \& Ennis, 1998; Zins, 2000). Especially the use of (electronic) information retrieval systems as a possible strategy in the collection of information is an important research topic within the domain of 'information- 
searching behavior' (Ingwersen, 1996; Spink, 1997), which is also often the domain of the Library and Information Science. Since electronic information retrieval systems, like hypertext databases, online public access catalogues and particularly the Internet are widely used, it is not surprising that contemporary research on both 'information-seeking behavior' and 'informationsearching behavior' is mainly focusing on seeking and searching behavior while using electronic systems. 'Information-seeking behavior' and its sub set 'information searching behavior' are nested within the research area of 'information behavior'. Research in this larger field concerns not only intentional information behavior but also unintentional behavior; for instance, passively watching a television commercial (Wilson, 1999).

Thus, research concerning information problem solving, regarded from the nested cycles of Wilson (ibid), concerns unraveling the process of searching, acquiring, processing, organizing and presenting information. This more psychological point of view of getting grip of the processes involved is one side of the coin. The other side of the coin approaches the IPS process from a more educational point of view. It is not only important to gain more inside in the IPS process of students and to determine the problems students have with solving information-based problem, but is it also necessary to design instructional support to foster this ability. This view will be the focus of this special issue. Different instructional principles and support tools were studied, and will be reported in this issue. In the next section they will briefly discussed.

\section{Instructional Support in Information Problem Solving}

The skill of solving information problems can be characterized as a complex cognitive skill. It is often assumed that students master this skill on their own, but this is not self-evident. Students frequently use superficial strategies for searching and processing information and it can 
be concluded that students must learn how to solve information-based problems by acquiring transferable strategies. Guidelines for designing instruction promoting the development of the complex cognitive skill of information problem solving (IPS) are therefore needed. The studies presented in this issue contributed to formulating these guidelines for different kind of educational settings.

The first contribution by Walraven, Boshuizen and Brand-Gruwel is a review focusing on problems students of all ages (primary, secondary, and higher education) experience when solving information-based problems. The second contribution of De Vries, Van der Meij and Lazonder, and the third contribution of Kuiper, Volman and Terwel aimed at stimulating primary educational students (fifth and six graders) to use reflective web searching strategies and web skills. De Vries evaluated a new developed paper and worksheets and Kuiper embedded the instruction in an inquiry learning setting in which the discussion about the learned skills formed an important component. The fourth paper of Gerjets and Schorr focuses on secondary education students and addresses a training called CIS-WEB. The fifth contribution of Stadtler and Bromme and the sixth contribution of Wopereis, Brand-Gruwel and Vermetten is positioned at the tertiary level concerns the search process of adults. Stadtler focus on fostering laypersons' search process while searching for medical information by providing them with a metacognitive support tool. Wopereis addresses the necessity of embedded instruction in information problem solving in higher education.

The contribution Information Problem Solving: A Review of Problems Students Encounter and Instructional Solutions (Walraven et al.) reports a review of research aiming at determining what kinds of problems people experience when solving information-based problems using the WWW. Moreover, it also focuses on what kind of instructional support can 
foster students' information problem solving ability. To gain insight in these aspects Walraven et al. use a model describing the different skills of the whole process of Information problem solving as a frame of reference. Results reveal that especially teenagers and younger children have problems with defining the information problem. They are not able to formulate the central question and to determine the needed information. Furthermore, children as well as adults have problems specifying search terms and judge search results, in terms of making a selection of sites to be opened from the hitlist. Also, the judgment of sources (sites) and information on reliability, actuality and usability is difficult for students of all ages. Criteria that can be used for judging are not explicit for students. When processing information, reading of hypertext can also cause problems. Furthermore, problematic when solving information problems is the lack of regulation. Students of all ages become better searchers when they orientate, test, monitor, steering and evaluate the process constantly. The instructional and support methods reviewed in this article can be grouped based on several features: the way the instruction is offered (either embedded in the curriculum or as a separate course); the way the instruction is followed by participants (individually or collaboratively), tools used during the instruction, and the skills the instruction is addressing. It appears that most offered instructional support can be characterized as stand-alone instruction for individual use. Tools used differed from web-based portals or computer applications, to worked-out examples and visualizations, to worksheets. It is promising that the reviewed studies aimed at fostering the most problematic skills and that most of them are effective.

The contribution Supporting reflective web searching in elementary schools (De Vries et al.) describes two design experiments in which reflective web searching is implemented in six elementary classrooms. The authors define reflective web searching in three steps: (1) develop 
ownership over search questions, (2) interpret and personalize web content, and (3) adapt web content into personally meaningful answers. It stimulates the learner to relate existing knowledge and experiences to findings on the web, because he or she owns the question, interprets retrieved information, and adapts it into own wordings. To foster students reflective web searching a portal and a worksheet is developed, embedded in learning tasks and studied. In the first experiment 28 small groups of two till four students (fifth and six graders) worked during six lessons on a biology task. While accomplishing the task the students used the developed portal for searching the information and were guided through the process by the worksheet. The sheet consisted of two sections: 'Our question is', and 'Write down the answer you found below'. To determine the effect of the used portal and worksheet different kinds of data were collected (observation, field notes, informal evaluations and semi-structured interviews). Results reveal that reflective web searching was only partly realized. The children used the web from their own personal motives feeling ownership over the task and over their questions. However, the interpretation and adaptation of retrieved information occurred infrequently. In the second design experiment, the portal and worksheet were improved to raise the extent to which children locate, and adapt new information. In this experiment 16 small groups of students participated. Results reveal that when a portal provided the children with far more cues to base their navigational decisions on, its helps them to search goal-driven, and locate question-related information. On the other hand, it was found that only to a certain extent the children processed the information. The overall conclusion is that a portal can successfully limit the search space and a worksheet can stimulate students to stick to their question, and relate questions to (provisional) answers.

The third paper Integrating critical Web skills and content knowledge: development and evaluation of a $5^{\text {th }}$ grade educational program (Kuiper et al.) describes (as the 
title tells us) the development and evaluation of an educational program aiming at acquiring Web skills in the context of a content knowledge domain, namely healthy food. Based on literature from three areas (Library and Information Science, Educational Science and Reading Research) Kuiper formulates three important web skills: Web searching skills, Web reading skills and Web evaluating skills. Searching skills include for example the ability to define appropriate key words and locate relevant information. Reading deals among others with the ability to handle hypertext Evaluating skills include the ability to assess the relevance, reliability and authority of information on the WWW. The mean instruction principle used in this study is that Web skills should be acquired within a relevant and meaningful context and not through isolated assignments. By embedding the teaching of Web skills within teaching and acquiring content matter, the intention is that these skills become meaningful for students. Four $5^{\text {th }}$ grade teachers and in total 82 students worked during eight weeks on structured assignments, and practice and discussed the skills. A variety of data were collected both on the experiences of the teachers and on the learning processes of students, with a view to an in-depth study of the program. Lesson observations, field notes and face-to-face interviews with teachers were combined with student interviews, student questionnaires, and final student assignments. Results reveal that in general, the teachers were able to work well with the program, although it seems important that teachers are willing to invest, and that the use of specific didactics (like discussion) are critical for success. With regard to students' learning results, all classes show knowledge gain with regard to both the subject healthy food and Web skills, but it should be mentioned that there is no comparison with a control condition. The program in which web skills are embedded in inquiry tasks is a step in the right direction. However, programs should address a thorough connection between Web literacy skills and the curriculum content to stimulate meaningful and deep 
learning.

The fourth contribution Competent information search in the World Wide Web:

Development and evaluation of a web training for pupils (Gerjets \& Schorr) describes the development and empirical evaluation of the web training CIS-WEB (Competent Information Search in the World Wide $W E B$ ) which aims to convey prerequisite knowledge and skills that are necessary for a competent search for information on the web. The web training focuses on how to competently handle information on the web and is based on two theoretical analyses. First, a conceptual analysis of information search from the perspective of media literacy research and information retrieval research was conducted and yielded a set of five pivotal content aspects that need to be covered by a web training. Each of these content aspects is characterized by declarative and procedural knowledge components which are necessary for the pursuit of a competent search for information on the web. Second, the authors conducted a task analysis which conceptualizes the search for information on the web as a problem-solving process and which allows to systematically distinguish between different types of information problems. In the empirical part of the paper two classroom studies are reported. In Study 1 the widespread training concept of a technically oriented Internet training for pupils was evaluated and it was shown that no substantial improvement of web searching skills can be expected from this type of treatment. In Study 2 it was shown that the web training CIS-WEB improves pupils' declarative knowledge of the web as well as their search performance, thereby outperforming the conventional Internet training used in Study 1.

The fifth paper Effects of the metacognitive computer-tool met.a.ware on the web search of laypersons (Stadtler \& Bromme) addresses how laypersons search information for themselves about health-related issues. Stadtler states that the competent use of these often complex and 
heterogeneous information provisions cannot be taken for granted, because many Internet users are lacking the necessary metacognitive prerequisites. To foster and stimulate students' use of metacognitive strategies while searching for information when solving health-related problems a tool met.a.ware is developed. This tool focuses not only on two types of metacognitive processes by prompting students, namely: evaluating information, and monitoring one's own comprehension, but also presents an ontological classification, such as: causes of a disease, consequences of a medical condition, or therapy. The ontological classification specially aims at focusing laypersons on relevant categories of the search topic. To evaluate the effect of the tool 120 undergraduate University students, divided in four conditions with different kinds of metacognitive support, participated and solved a task about cholesterol. Results reveal that concerning the knowledge acquisition students who received metacognitive support using 'Metaa-ware' had afterwards significantly more factual knowledge on the topic cholesterol. However, this result was only partly support by the results of the subject matter comprehension test. Furthermore, ontological classification incorporated in met.a.ware was used efficiently by the laypersons. People working without ontological classification structured their notes insufficiently, compared to the people with the classification. In general, using metacognitive prompts for monitoring and evaluation increased knowledge and providing ontological classification helps to structure notes taken during Internet research and focuses laypersons on salient ontological categories.

The last contribution The effect of embedded instruction on solving information problems (Wopereis, et al.) studied the effect of embedded instruction in information problem solving in a distance education setting. The instruction was designed according to new theories promoting instructional design for learning complex skills. Two main principles in these theories were 
starting point in designing the embedded instruction: real-life tasks as the driving force for learning, and process oriented instruction. The instruction was embedded in a competence-based and web-based Psychology curriculum for research methodology and lasted 25 weeks. Sixteen Psychology students from an Open University participated as a member of the experimental group or the control group. Both conditions followed the same course, but the in the experimental condition the IPS instruction was embedded. During the pre- and posttest all students solved an information-based problem while thinking aloud. For solving the information problem the students had the possibility to search for information not only on the Internet, but they had also books to their disposal. The analysis of these protocols revealed that students who received the embedded instruction judged the information found more often after the intervention than the students who did not received the instruction. Furthermore, students of the experimental condition were better able to regulate their process afterwards. A final remark concerns the integrated instruction. Although the embedded instruction contributes to solving information problems more efficiently in this group of students, the effect could be more substantial. An important prior condition was that the instruction had to fit in an existing instructional framework, and that only one (although large) information problem could be dealt with in the present course. As can be derived from literature, for learning complex cognitive skills it is important that students face different problems in different contexts.

A discussion chapter concludes this Special Issue. Ard Lazonder from the Twente University of the Netherlands and Jean-François Rouet from the University of Poitiers (France) critically discuss the different contributions. They also reflect on the state of the art regarding instructional support for fostering students' problem solving ability. 
Conclusion and future directions

The described studies all concerned instructional support to foster students' information problems solving ability. It can be concluded that in these studies different sub skills of the IPS skill or certain aspects are supported. For instance, the worksheet used in the study by De Vries et al. concerned students reflective use of web skills like the formulation of questions and answers. The research of Stadtler and Bromme focused especially on the metacognitive aspects during searching for medical information. The study of Kuiper et al. concentrated on searching, reading and evaluating information, but did not especially addressed the regulation of the skills involved. The study of Wopereis et al. tried to give support on all different aspect of the whole information problem solving skill as defined by Brand-Gruwel et al. (2005). In this study the emphasis also was on the regulation of the process. The study of Gerjets and Schorr also addresses several sub skills of information problem solving but neglect how the information retrieved is finally synthesized into cogent, productive uses. Taken the different aspects addressed in these studies and link them to the results Walraven found in her review, it could be concluded that involved researchers did the right thinks. Walravens' research show that regulation, reflection and evaluation during the process of solving information problems is often problematic and support is needed.

When reviewing the tools and methods used to organize the support it shows that in the studies presented in this issue a variety of tools and methods were used. De Vries used a portal to structure information for students and to help them to search and select the needed information. A task-specific portal supporting students in searching and selecting relevant sources can foster the interpretation and personalization of retrieved information. Because spending lots of time on searching and locating relevant information comes at the cost of processing it (Jones, 2002). 
Important is, as revealed, how the information is structured and the portal is designed.

Furthermore, De Vries supported reflective web use by giving students worksheets. Also in the study of Wopereis students were guided through the process by providing them with processworksheets. Students answered questions concerning the different steps and the regulation of the process. Stadtler used prompts to draw students' attention to metacognitive aspect of the search process. Prompting the learner to execute specific metacognitive processes, in this case monitoring and evaluation prompts, on a regular basis is especially suitable in cases where learners are generally capable of executing metacognitive processes, but do not or only seldom apply these strategies spontaneously (Bannert, 2004). Kuiper in her research used discussion sessions to make students more aware of the critical web skills involved in the process of searching, selecting, evaluating and processing information. All these used tools and methods aimed at helping students to become more effective and efficient information problem solvers, and not unimportant to process information in depth and construct knowledge.

Future research should address how instructional support to foster students' information problem solving skill can best be designed. The instruction must be adaptive and fit to the learners needs. Aspects as regulation, evaluation and judgment of information, used search strategies, processing of information are important aspects to focus on in order to stimulate students to construct knowledge. Effects of different instructional methods must be further studied. For instance, effects of collaborative learning or adaptive support are interesting topics in this matter.

\section{References}

Bawden, D. (2001). Information and digital literacies: a review of concepts. Journal of Documentation, 57, 218-259. 
Bannert, M. (2004). Designing metacognitive support for hypermedia learning. In H.

Niegemann, D. Leutner \& R. Brünken (Eds.), Instructional Design for MultimediaLearning. (pp. 19-30). Münster: Waxmann.

Brand-Gruwel, S., Wopereis, I., \& Vermetten, Y. (2005). Information problem solving by experts and novices: Analysis of a complex cognitive skill. Computers in Human Behavior, 21, 487-508.

Eisenberg, M. B., \& Berkowitz, R. E. (1990). Information problem-solving: The big six skills approach to library and information skills instruction. Norwood, NJ: Ablex.

Eisenberg, M. B., \& Berkowitz, R. E. (1992). Information problem-solving: the big skills approach. School Library Media Activities Monthly, 8(5), 27-29, 37, 42.

Eisenberg, M. B., \& Berkowitz, R. E. (2000). The BIG6 collection: The best of the Big6 newsletter. Worthington, $\mathrm{OH}$ : Linworth.

Eisenberg, M. B., \& Johnson, D. (2002). Learning and teaching information technology. Syracuse, NY: ERIC Clearinghouse on Information \& Technology (No. ED465377). Retrieved July 7, 2003, from http://ericit.org/digests/EDO-IR-2002-04.pdf

Hill, J. R. (1999). A conceptual framework for understanding information seeking in open-ended information services. Educational Technology, Research and Development, 47(1), 5-27.

Hölscher, C., \& Strube, G. (2000). Web search behavior of Internet experts and newbies. Computer Networks, 33, 337-346.

Ingwersen, P. (1996). Cognitive perspectives of information retrieval interaction: Elements of a cognitive IR theory. Journal of Documentation, 52, 3-50.

Jones, B. D. (2002). Recommendations for implementing internet inquiry projects. Journal of Educational Technology Systems, 30(3), 271-291. 
Kuhlthau, C. (1993). Seeking Meaning: A Process Approach to Library and Information Services. Norwood, NJ:Ablex.

Lazonder, A. W. (2000). Exploring novice users' training needs in searching information on the WWW. Journal of Computer Assisted Learning, 16, 326-335.

Lazonder, A. W. (2003). Principles for designing web searching instruction. Education and Information Technologies, 8, 179-193.

Marchionini, G. (1995). Information-seeking in electronic environments. New York: Cambridge University.

Marchionini, G. (1999). Educating responsible citizens in the information society. Educational Technology, 39(2), 17-26.

Moore, P. (1995). Information problem solving: a wider view of library skills. Contemporary educational psychology, 20, 1-31.

Shapiro, J. J., \& Hughes, S. K. (1996). March/April. Information literacy as a liberal art: enlightenment proposals for a new curriculum. Educom Review, 31(2). Retrieved October, 31, 2005. Available from www.educause.edu/pub/er/review/reviewarticles/31231.html.

Spink, A. (1997). Study of interactive feedback during mediated information retrieval. Journal of the American Society for Information Science, 48, 382-394.

Spitzer, K. L. (2000). What every educator should know about information literacy. In M.B. Eisenberg \& R.E. Berkowitz (Eds.), The Big6 collection: The best of the Big6 newsletter (pp. 3-13). Worthington, OH: Linworth.

Sutcliffe, A., \& Ennis, M. (1998). Towards a cognitive theory of information retrieval. Interacting with Computers, 10, 321-351. 
Wilson, T. D. (1999). Models in information behaviour research. Journal of Documentation, 55(3), 249-270.

Wolf, S. E., Brush, T., \& Saye, J. (2003). Using an information problem-solving model as a metacognitive scaffold for multimedia-supported information-based problems. Journal of Research on Technology in Education, 35, 321-341.

Zins, C. (2000). Success, a structured search strategy: rationale, principles, and implications. Journal of the American Society for Information Science, 51, 1232-1247. 